\title{
Caracterização físico-química do material particulado emitido por forno de pizzaria: estudo de caso da Pizzaria Achiropizza
}

\author{
Physical chemical characterization of particulate matter emitted fireplace pizzeria: a \\ case study of achiropizza pizzeria
}

\author{
Daniel Mota \\ Universidade de São Paulo,SP, Brasil
}

\begin{abstract}
Resumo
O presente artigo tem por objetivo caracterizar físico e quimicamente o material particulado emitido por forno de pizzaria. Foi realizado um estudo de caso em uma pizzaria localizada no centro de São Paulo - Pizzaria Achiropizza. O estudo consistiu na amostragem do ambiente interno e externo (junto à chaminé) antes e depois de ser ligado forno. Utilizando um amostrador de material particulado fino (MiniVol), foi realizada a amostragem. Através das técnicas de análise, gravimetria, black carbon e fluorescência de raios- $x$ (FRX) aferiu-se os resultados. Os resultados mostraram grande variação na concentração de massa depositada sobre os filtros, variando de 44,4 à $389,7 \mathrm{~g} / \mathrm{m} 3$ para o ambiente interno e de 78,9 à 20380,0 g/m3 para o ambiente externo. No tocante ao black carbon a margem de variação é menor para o ambiente interno, de 2,1 à 14,9 g/m3, e para o externo a variação é de 32 à $5757,8 \mathrm{~g} / \mathrm{m3}$, a análise de fluorescência de raios- $x$ (FRX) mostrou a predominância do Potássio, Fósforo, Cloro e Enxofre.
\end{abstract}

Palavras-chave: Material Particulado, Forno de Pizzaria, Análise Físico-Química.

\begin{abstract}
This article aims to physico-chemical characterization of particulate matter emitted per oven pizzeria. We conducted a case study in a pizzeria located in downtown São Paulo - Pizzaria-Achiropizza, the case study consisted of a sampling of the internal and external environment (by the fireplace) before and after being turned on the oven. Using a fine particulate sampler (MiniVol), sampling was performed and further through the techniques of analysis, gravimetric, black carbon and $x$-ray fluorescence (XRF) aferiu the results. The results show a wide variation in the concentration of deposited mass on the filters varying from 44.4 to $389.7 \mathrm{~g} / \mathrm{m} 3$ to the internal environment and the $20380.078 .9 \mathrm{~g} / \mathrm{m} 3$ to the external environment. With regard to carbon black margin of variation is low to internal environment, from 2.1 to $14.9 \mathrm{~g} / \mathrm{m} 3$ and the outer variation is 32 to $5757.8 \mathrm{~g} / \mathrm{m} 3$, the fluorescence analysis $x$-ray (XRF) showed the predominance of Potassium, Phosphorus, Sulfur and Chlorine.
\end{abstract}

Keywords: Particulate Matter, Physics and Chemistry Analysis, Fireplace Pizzaria. 


\section{Introdução}

A preocupação com a questão da poluição ambiental tem crescido consideravelmente, sobretudo devido ao alerta da chamada crise ecológica. Com o crescimento da população mundial e desenvolvimento tecnológico, ampliou-se a capacidade da sociedade em causar prejuízos ao meio ambiente. Gerando, por outro lado, também a esperança e a crença de que por meio da ciência e da tecnologia adviriam importantes contribuições para o surgimento da sustentabilidade planetária.

O desenvolvimento das sociedades humanas consiste em uma história marcada por alterações impostas aos sistemas naturais do mundo, principalmente advindas de atividades antrópicas, a fim de atender a modos de vida mais sofisticados e confortáveis para um número cada vez mais elevado de habitantes.

Atividade antrópica é toda ação humana (obra civil, atividade agrícola, industrial, mineração e outras formas de uso e ocupação do solo) que altera processos, propriedades ou características físicas, químicas ou biológicas, ou interferem em usos preexistentes de um determinado ambiente (FORNASARI FILHO et al, 1992).

Todas essas atividades, assim como a queima da lenha em pizzarias e também processos naturais, podem ser fonte de poluentes atmosféricos, alguns dos quais podem ser nocivos ao meio ambiente e à saúde humana. O Material Particulado (MP) um dos mais agressivos ao homem - é definido como uma mistura de partículas sólidas e líquidas em suspensão na atmosfera (SEINFELD e PANDIS 1998).

É possível ainda caracterizar o material particulado (MP) de acordo com seu tamanho, em partículas finas (partículas com diâmetro aerodinâmico menor que 2,5m) e grossas (partículas com diâmetro aerodinâmico entre 2,5 e 10m), (BIRD, 2002).

Quanto menor o tamanho da partícula maior a chance de causar problemas na saúde, principalmente no sistema respiratório. A partícula menor consegue atravessar todo o trato respiratório e se alojar nos alvéolos pulmonares. Em seus estudos, Saldiva (2008) faz um apelo aos médicos pneumologistas para maior atenção a exposição das pessoas que estão diretamente expostas a queima da lenha. Os efeitos devido a exposição podem ser de uma simples infecção até em casos mais extremos ocasionar a morte.

Segundo dados do Serviço Brasileiro de Apoio à Micro e Pequenas Empresas (SEBRAE) a cidade de São Paulo possui aproximadamente 5.850 mil pizzarias (em sua maioria micro e pequenas empresas) que produzem cerca de 42,9 milhões de unidades por mês. Totalizando, desta feita, mais de 1 milhão de pizzas por dia que gera uma receita de $R \$ 5$ bilhões por ano.

Desde 1985, por conta do relevante consumo de pizzas na cidade de São Paulo, o dia 20 de julho ficou intitulado como o "Dia da Pizza" na cidade - dia esse em que o consumo aumenta na ordem de $20 \%$, gerando por consequência, um aumento nas emissões de material particulado.

Por fim, o artigo encontra a sua relevância, além dos motivos anteriormente citados, no tangente a escassez de estudos sobre o assunto no Brasil. Citando ainda o agravante de que não há legislação específica para lidar com o problema. De sorte que o tema por ora tratado assegura caráter de originalidade e serventia tanto para o estudo acadêmico como para sinalizar olhares para uma possível abordagem técnico-ambiental da questão.

\section{Fundamentação teórica}

Essa seção apresenta o estado da arte e os principais conceitos e pontos para o desenvolvimento da pesquisa.

\subsection{Cocção da pizza e utilização da lenha como recurso energético}

Tornando-se popular e apreciada em praticamente todo o mundo, a prática de cozimento da pizza tem chamado a atenção de pesquisadores acerca do potencial poluidor que a atividade pode causar ao meio ambiente e a quem está exposto na pizzaria.

Embora não seja unanimidade, uma parte considerável das pizzarias fazem uso dos chamados "forno à lenha" utilizando assim, a mesma como fonte de energia e, por consequência, emitindo poluentes para a atmosfera, haja vista que é considerado poluente atmosférico "qualquer substância presente no ar que pela sua concentração venha torná-lo impróprio, ofensivo ou nocivo à saúde, inconveniente ao bem estar público, danoso aos materiais, à fauna e à flora ou prejudicial à segurança". (CONAMA, 1990)

As emissões por fornos de pizzarias enquadram-se na classificação de poluentes primários, ou seja, são emitidos diretamente pelas fontes emissoras como as chaminés das mesmas (SEINFELD \& PANDIS, 1998).

No entanto, segundo KEMP 1989, estes poluentes podem, na baixa atmosfera, sofrer transformações e reações fotoquímicas dando origem a poluentes denominados secundários, ressaltando que a distribuição das concentrações de poluentes na atmosfera depende das condições de emissão e das condições meteorológicas, podendo alguns poluentes ser transportados a grandes distâncias antes de atingirem o nível do solo (KEMP, 1989).

Já no campo energético a madeira (comumente chamada de lenha) sempre ofereceu histórica contribuição para o desenvolvimento da humanidade, tendo sido sua primeira fonte de energia - sendo inicialmente empregada para aquecimento e cocção de alimentos. Ao longo dos tempos passou a ser utilizada como combustível sólido, líquido e gasoso, em processos para a geração de energia mecânica, elétrica e térmica (BRITO, 2007). 
Sem considerar as quantidades mínimas de nitrogênio e de outros elementos, segundo estudos da Universidade Federal de Minas Gerais (UFMG), no artigo "a queima da madeira", a análise química elementar da lenha mostra que a sua constituição é de aproximadamente $50 \%$ de carbono, $6 \%$ de nitrogênio e $44 \%$ de oxigênio, sendo que a ausência total de enxofre é uma das vantagens deste combustível uma vez que o mesmo está relacionado à chuva ácida.

Ainda segundo estudos da (UFMG), quimicamente a lenha é heterogênea, sendo constituída basicamente por três polímeros: celulose, hemicelulose e lignina numa proporção de aproximada de 50:20:30. Em menor quantidade, existem outros componentes presentes na lenha, são compostos de baixo peso molecular chamados extrativos, encontrados notadamente na casca e englobando óleos, terpenos, corantes e graxas.

\subsection{Poluição de Ambientes Interiores}

No Brasil o número de estudos acerca do assunto ainda é pequeno. No mundo, vários estudos têm tentado mensurar a quantidade de partículas (concentração e tamanho) que são emitidas por fornos de pizzarias durante o processo de preparo da pizza (HUSSEIN et al, 2006). Desta feita, são de grande importância os estudos sobre a avaliação do risco em microambientes internos, representado por pizzarias e restaurantes (BRAUER et al, 2000).

O risco é decorrente à exposição das pessoas aos contaminantes. Estudos apontam que deve ser levado em consideração, entre outros fatores, a presença ou ausência de ar-condicionado no ambiente, haja visto a proibição ao cigarro nos ambientes fechados. Desta forma, outra fonte de poluição local são as emissões decorrentes da queima da lenha. A relevância quanto a presença ou ausência de ar-condicionado, diz respeito a estudos, que embora recentes, apontam que os sistemas de ar-condicionado também são importantes fontes de poluição de ambientes interiores. (GIODA e AQUINO NETO, 2003).

Por conta disso, o Ministério da Saúde publicou a Portaria 3523 de 28 de agosto de 1998, contendo Regulamento Técnico que visa "promover o estabelecimento de medidas referentes à limpeza dos sistemas de climatização e medidas específicas de padrões da qualidade do ar identificando poluentes de natureza física, química e biológica com suas respectivas fontes, visando a prevenção de riscos à saúde dos ocupantes desses ambientes".

Este regulamento técnico surge em decorrência da ampla e crescente utilização de sistemas de ar condicionado no país, considerando a preocupação com a saúde, o bem-estar, o conforto e a produtividade dos ocupantes dos ambientes climatizados e a sua inter-relação com a variável qualidade de vida.
Considerando a necessidade de serem aprovados procedimentos que visem minimizar o risco potencial à saúde dos ocupantes dos ambientes climatizados, fica estabelecido um Regulamento Técnico que deve ser aplicado aos ambientes climatizados de uso coletivo.

Neste Regulamento Técnico fica estabelecido que: devem ser realizados procedimentos de verificação visual do estado de limpeza, remoção de sujidades por métodos físicos de modo a garantir a eficiência de todos os componentes dos sistemas de climatização. Além de estabelecer medidas específicas referentes a padrões de qualidade do ar em ambientes climatizados - no que diz respeito a definição de parâmetros físicos e composição química do ar de interiores. Assim como também a identificação dos poluentes de natureza física, química e biológica.

\subsection{A combustão da lenha e suas emissões}

Considerando a ausência de fontes de poluição interna (queima de cigarro e sistemas de ar condicionado), de acordo com Mello, a combustão completa da lenha em fornos a lenha produzem emissões atmosféricas de material particulado, compostos orgânicos voláteis (covs), óxidos de nitrogênio e em menor quantidade óxido de enxofre, e no processo de combustão incompleta da lenha é caracterizado pelo alto nível de compostos orgânicos e altas emissões de monóxido de carbono.

No entanto, ainda segundo Mello, existe um ciclo no processo de cocção em que as concentrações desses poluentes variam. Após o período inicial de elevada queima da lenha, e por consequência altas taxas de emissão, inicia-se uma nova fase, agora caracterizada por menor queima da lenha, constituindo assim um número menor de ciclos de alta emissão seguido por numerosos ciclos de baixa emissão (MELLO, 2002).

De maneira mais detalhada, (Bologa et al 2009) diz que o processo de queima da lenha é realizado em três ciclos e não apenas dois, conforme estudos de Mello. Sendo que o primeiro ciclo é caracterizado pelo aquecimento da madeira e posterior perda da umidade, o segundo ciclo, esse marcado pelo aumento da temperatura e, por consequência, a quebra química da lenha com posterior desprendimento de gases e voláteis.

A terceira fase é caracterizada pela queima do restante da lenha, onde se mais lenha não for adicionada, o processo de combustão é desacelerado, no entanto, o processo de liberação de gases é mantido até a queima total da lenha (KEMP, 2009).

Outros estudos mostram que além dos ciclos da queima da lenha, deve-se compreender os parâmetros que influenciam os fatores de emissão tais como: tamanho de abertura da face do forno, eficiência do exaustor, tamanho da pizzaria e o sistema de ventilação do local (G. BUONANNO et al, 2010). 


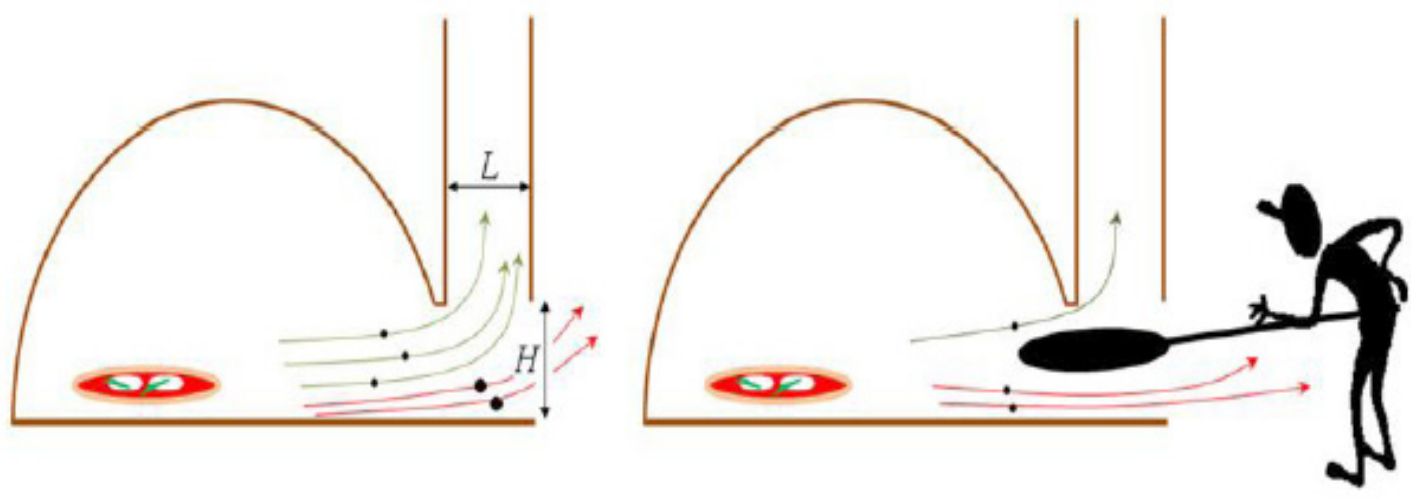

Figura 1 Relação entre saída de poluentes e desenho do forno.

Fonte: G. BUONANNO et al. / Atmospheric Environment, 2010

Corroborando com os estudos de G.Buonanno, Ashrae, afirma que a abertura da face do forno, está diretamente relacionada com a parcela do material particulado que vai para a área interna da pizzaria.

Ainda segundo Ashrae, maiores aberturas da face do forno, permitem que elevadas concentrações do material particulado sejam lançadas no ambiente interno e por consequência uma maior exposição das pessoas aos contaminantes. No tocante a eficiência do exaustor, temos que uma maior largura do mesmo, possibilita uma ascensão mais acentuada do material particulado, acarretando, portanto uma maior dispersão dos poluentes através da chaminé, (ASHRAE, 2007).

\section{Método de Pesquisa}

A metodologia desenvolvida no presente estudo foi pautada nos seguintes instrumentos: estudo das referências bibliográficas acerca do tema em questão, buscando um forte e relevante embasamento teórico para a realização do trabalho; visita ao local para realização da amostragem, (a coleta de dados se deu nas dependências da Pizzaria Achiropizza localizada no bairro do Bixiga, na cidade de São Paulo -SP); medições no interior e no exterior da pizzaria (junto à chaminé); análise do material coletado por diferentes técnicas complementares e elaboração de relatório de resultados.

\subsection{Equipamentos e técnicas de análise}

\section{Mini Vol Portable}

O MiniVol foi o equipamento utilizado para a realização da parte prática do estudo. O aparelho pode ser configurado para coletar MP2,5, MP10 ou partículas totais em suspensão (PTS), mas não simultaneamente (para a pesquisa foi configurado para coletar MP2,5). Opera com vazão de $5 \mathrm{l} / \mathrm{min}$ e faz uso de filtros de policarbonato com diâmetro de $47 \mathrm{~mm}$. A separação de 10 ou 2,5 é conseguida por impactação. A fração total é amostrada quando se remove o impactador.

\section{Gravimetria}

A determinação da concentração em massa do material particulado foi realizada pelo método gravimétrico. A gravimetria consiste na pesagem dos filtros antes e depois da amostragem a fim de se obter a concentração em massa do material depositado. Antes de qualquer pesagem, os filtros permaneceram por um período de 24 horas em um ambiente com controle de temperatura e umidade relativa do ar (T $220 \mathrm{C}$ e UR $45 \%$ ), evitando interferência desses fatores nos resultados.

\section{Análise de black carbon (carbono elementar) atra- vés do método de refletância}

A análise de refletância foi utilizada para determinar a concentração de black carbon presente nos filtros amostrados, predominante na fração fina do material particulado. A técnica baseia-se na propriedade do composto possuir alta seção de choque de absorção de luz na região do visível. Foi utilizado um refletômetro Smoke Stain Refletometer, Diffusion System, modelo M43D. O filtro é iluminado por uma lâmpada de tungstênio e a luz refletida é detectada por um sensor. Quanto menor a intensidade dessa luz, maior é a quantidade de black carbon presente na amostra, pois este estaria absorvendo uma parcela da luz incidente.

\section{Fluorescência de Raios- X (FRX)}

A técnica analítica instrumental de FRX - Fluorescência de raios $X$ tem sido utilizada na avaliação quali-quantitativa da composição química em vários tipos de amostras, de interesse agropecuário, agroindustrial, geológico e ambiental. Esta técnica é de grande importância na análise multi-elementar em amostras oriundas de sistemas biológicos, pois pode determinar tanto macro elementos como Cálcio-Ca e Potássio-K, como elementos traços, como Cobre- $\mathrm{Cu}$ e Chumbo- $\mathrm{Pb}$, ou também elementos não-metais como Enxofre-S.

Após as análises de gravimetria e refletância, os filtros foram preparados para a fluorescência e cromatografia: são colocados num suporte específico onde $1 / 4$ é recortado e afixado num anel, ficando assim pronto para análise 
por FRX . Cada amostra é analisada por 20 minutos. O espectro obtido juntamente com os dados de calibração do aparelho, são analisados em software específico para obtenção da concentração elementar em ug.m-3 .

\section{Resultados e Discussão}

A presente seção destina-se a apresentação e explanação dos resultados na intenção de atender ao objetivo que fora estabelecido.

\subsection{Pizzaria Achiropizza}

Localizada no tradicional bairro do Bixiga, Rua 13 de maio 513, região central de São Paulo, a Pizzaria Achiropizza faz uso do chamado "forno à lenha" e não dispõe de sistema artificial de climatização. A troca de ar ocorre exclusivamente pela porta, sendo portanto, a climatização artificial uma variável a menos no processo de caracterização do material particulado, uma vez que, conforme já dito anteriormente, o sistema de ar condicionado é uma importante fonte emissora de poluentes no ambiente interno. (GIODA e AQUINO NETO, 2003).

Diferente de outros estabelecimentos que mesmo intitulados de pizzaria também comercializam outros produtos, tais como massas, sopas, carnes e pizzas, a Achiropizza comercializa somente pizzas, uma vez que, de acordo com estudos de Congong He et al, o tipo de material particulado presente em uma residência, restaurante ou pizzaria também é influenciado pela composição do material a ser consumido assim como a técnica de preparo do mesmo, onde o grelhar, fritar e cocção da pizza podem variar no número e tipo de partículas para o ambiente durante a emissão, ( CONGRONG et al 2007).
Para a cocção da pizza, a pizzaria utiliza a chamada lenha de eucalipto, provida do reflorestamento em substituição à lenha de mata nativa, onde a última fora explorada demasiadamente, haja visto ser a fonte de energia mais antiga usada pelo homem e continua ter grande importância na matriz energética brasileira (REZENDE E FONSECA, 2004).

\subsection{Instrumentação da amostra}

A realização do experimento ocorreu entre os dias 20 e 23 de Outubro de 2011, compreendendo os dias de maior movimento na pizzaria, início na quinta- feira e término na madrugada de domingo.

Dispondo de dois aparelhos MiniVol, e fazendo uso de filtros de policarbonato com $47 \mathrm{~mm}$ de diâmetro, simultaneamente foram programados para operarem duas vezes ao dia, antes e depois de aceso o forno, no salão da pizzaria (ambiente interno) e junto à chaminé da pizzaria (ambiente externo), possibilitando a quantificação e identificação do material particulado emitido.

De modo a conseguir uma amostra do material particulado emitido pela chaminé, e não apenas a caracterização do ambiente externo, foi acoplado um duto junto a saída da chaminé.

O Mini Vol foi programado para funcionar no primeiro período das 11 às 17 hs e no segundo das 19 à $01 \mathrm{~h}$, sendo amostrado o antes e o depois de aceso o forno. Os filtros eram trocados no intervalo entre o primeiro e o segundo período de amostragem, sendo tomado os devidos cuidados no manuseio dos mesmos.

A amostragem do ambiente interno ocorre conforme esperado, ou seja, o aparelho funcionou nos dias e horário programado, contabilizando 12 horas diárias. A amostragem externa não se deu da mesma forma, uma vez que decorrente da sujidade emitida pela chaminé,

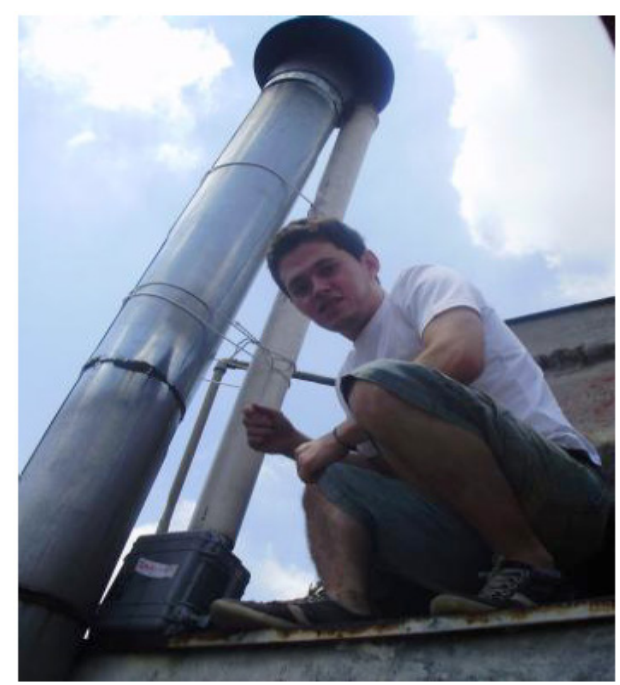

Figura 2 Duto que liga a chaminé ao aparelho

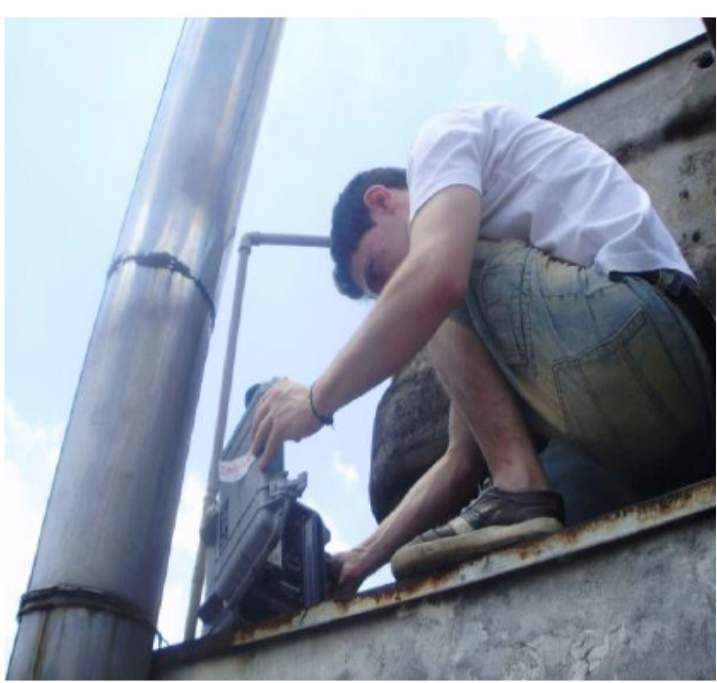

Troca de filtro e leitura de fluxo e horímetro 
ocasionou o entupimento dos filtros, portanto amostrado os seguintes dias com seus respectivos tempos em minutos de amostra: quinta-feira (6min), sábado (30min) e domingo (24min), na sexta-feira (21/10) decorrente de algum imprevisto técnico-operacional, o Mini Vol não funcionou para o período noturno, assim como para o período diurno no dia (23/10) domingo.

As fotos mostram a chaminé da pizzaria com 2,15 m de altura e 0,87 m de diâmetro. A fumaça da chaminé foi "canalizada" de forma que o amostrador coletasse somente o material particulado proveniente do forno a lenha, e não do ambiente como um todo. Porém, a alta concentração do poluente fez com que os poros do filtro fossem rapidamente entupidos. Sugestões serão fornecidas no final do artigo.

\subsection{Análise dos resultados}

As tabelas abaixo mostram os resultados obtidos para o ambiente interno e externo da pizzaria. A coluna Massa $(\mathrm{g} / \mathrm{m} 3)$, refere-se à massa depositada sobre o filtro em cada dia, a coluna BC ( $\mathrm{g} / \mathrm{m} 3)$ é referente a concentração de black carbon presente nos filtros amostrados.

Os valores obtidos para o ambiente interno mostram que em todos os casos houve um aumento na concentração, após aceso o forno, do dia 20 ao dia 22, haja vista a queima da lenha ser maior no final de semana. O mesmo vale para o black carbono. Observou-se uma diminuição da concentração interna após o forno ser aceso, o que pode-se justificar ao fato da chaminé do mesmo funcionar como um exaustor para o ambiente interno, sugando o ar do salão para dentro do forno e consequentemente para o exterior da pizzaria. Porém esse comportamento é contrário para o BC, cujas concentrações foram mais altas com o forno aceso.

Decorrente de imprevisto técnico-operacional, os dias 21/10 e 23/10 (área externa) para o período noturno e diurno respectivamente ficaram sem ser amostrados.

\begin{tabular}{ccccc}
\hline Data & Hora & $\begin{array}{c}\text { Tempo de amostragem } \\
\text { (minutos) }\end{array}$ & $\begin{array}{c}\text { Massa } \\
\left(\mu \mathrm{g} / \mathrm{m}^{3}\right)\end{array}$ & $\begin{array}{c}\mathrm{BC} \\
\left(\mu \mathrm{g} / \mathrm{m}^{3}\right)\end{array}$ \\
\hline $20 / 10 / 2011$ & $11-17 \mathrm{hs}$ & 360 & 98,1 & 5,7 \\
$20 / 10 / 2011$ & $19-01 \mathrm{hs}$ & 360 & 49,4 & 3,9 \\
$21 / 10 / 2011$ & $11-17 \mathrm{hs}$ & 360 & 133,3 & 4,8 \\
$21 / 10 / 2011$ & $19-01 \mathrm{hs}$ & 360 & 61,1 & 7,0 \\
$22 / 10 / 2011$ & $11-17 \mathrm{hs}$ & 360 & 389,7 & 4,8 \\
$22 / 10 / 2011$ & $19-01 \mathrm{hs}$ & 360 & 293,9 & 14,9 \\
$23 / 10 / 2011$ & $11-17 \mathrm{hs}$ & 360 & 131,4 & 2,1 \\
$23 / 10 / 2011$ & $19-01 \mathrm{hs}$ & 360 & 44,4 & 6,0 \\
\hline
\end{tabular}

Figura 3 Concentrações de massa e black carbon dentro da pizzaria (antes e depois do forno ser aceso).

\begin{tabular}{cccrr}
\hline Data & Hora & $\begin{array}{r}\text { Tempo de amostragem } \\
\text { (minutos) }\end{array}$ & $\begin{array}{r}\text { Massa } \\
\left(\mu \mathrm{g} / \mathrm{m}^{3}\right)\end{array}$ & $\begin{array}{r}\mathrm{BC} \\
\left(\mu \mathrm{g} / \mathrm{m}^{3}\right)\end{array}$ \\
\hline $20 / 10 / 2011$ & $11-17 \mathrm{hs}$ & 360 & 80,8 & 3,6 \\
$20 / 10 / 2011$ & $19-01 \mathrm{hs}$ & 6 & 8616,7 & 612,0 \\
$21 / 10 / 2011$ & $11-17 \mathrm{hs}$ & 360 & 78,9 & 3,2 \\
$21 / 10 / 2011$ & $19-01 \mathrm{hs}$ & 0 & 0,0 & 0,0 \\
$22 / 10 / 2011$ & $11-17 \mathrm{hs}$ & 360 & 223,6 & 5,4 \\
$22 / 10 / 2011$ & $19-01 \mathrm{hs}$ & 30 & 20380,0 & 5138,7 \\
$23 / 10 / 2011$ & $11-17 \mathrm{hs}$ & 0 & 0,0 & 0,0 \\
$23 / 10 / 2011$ & $19-01 \mathrm{hs}$ & 24 & 17150,0 & 5757,8 \\
\hline
\end{tabular}

Figura 4 Concentrações de massa e black carbon fora da pizzaria, junto á chaminé (antes e depois do forno ser aceso). 
A concentração no ambiente externo, das 11 às 17 h, é praticamente igual nos dias 20 e 21 , aumentando consideravelmente no dia 22, sábado, provavelmente em decorrência da maior movimentação no salão (lembrando que a chaminé funciona como um exaustor para o ambiente interno) e também ao acúmulo de massa dentro no forno, com maiores valores para o sábado, dia de maior queima de biomassa.

É percebido um acúmulo de massa altamente superior em relação ao ambiente interno após ser aceso o forno, o que ocasionou o travamento do equipamento. Os valores encontrados são altíssimos, inclusive para o BC, mostrando as elevadas concentrações do poluente MP2,5 que são lançadas na atmosfera em decorrência da queima de lenha em forno para pizza.

Uma possível explicação para o não funcionamento do equipamento é em decorrência ao duto acoplado à chaminé. Ao ser emitida para a área externa, uma parcela considerável da fumaça adentrou no duto em altas concentrações, alcançando os filtros. Em virtude das elevadas concentrações ocorreu o entupimento dos mesmos e por isso o aparelho não pôde realizar a amostragem em tempo integral conforme programado, ou seja, seis horas.

\subsection{Caracterização elementar}

Logo abaixo a concentração elementar obtida pela análise de fluorescência de raios- $X$, para os ambientes interno e externo.

Como esperado, as maiores concentrações são para S e K, devido à queima da lenha (ASHRAE, 2007). Ainda $\mathrm{Na}$ e $\mathrm{Cl}$ devido ao sal presente nos ingredientes da pizza, sendo que o $\mathrm{Na}$ foi melhor caracterizado nas amostragens internas.

As figuras 6 e 7 mostram as concentrações elementares, por período, para os ambientes interno e externo.

No ambiente interno, além dos elementos acima citados, também foi detectada a presença de $\mathrm{Si}$, $\mathrm{Ca}$ e Fe, decorrentes de ressuspensão de poeira de solo e adentramento de particulado da rua, sendo que as maiores concentrações são no período noturno, quando a pizzaria encontra-se aberta ao público.

Na análise da fumaça da chaminé, como citado anteriormente, as maiores concentrações são para S, K, $\mathrm{Cl}$ e P.

\begin{tabular}{lll}
\hline & Ambiente interno & Ambiente externo \\
\hline $\mathrm{Na}$ & 1,30 & 0,16 \\
$\mathrm{Mg}$ & 0,00 & 0,02 \\
$\mathrm{Al}$ & 0,08 & 0,58 \\
$\mathrm{Si}$ & 0,57 & 0,42 \\
$\mathrm{P}$ & 0,03 & 4,85 \\
$\mathrm{~S}$ & 2,17 & 74,53 \\
$\mathrm{Cl}$ & 0,35 & 48,02 \\
$\mathrm{~K}$ & 1,44 & 2,63 \\
$\mathrm{Ca}$ & 0,20 & 0,16 \\
$\mathrm{Ti}$ & 0,02 & 0,02 \\
$\mathrm{~V}$ & 0,01 & 0,04 \\
$\mathrm{Cr}$ & 0,01 & 0,02 \\
$\mathrm{Mn}$ & 0,02 & 0,00 \\
$\mathrm{Fe}$ & 0,37 & 0,17 \\
$\mathrm{Ni}$ & 0,01 & 0,00 \\
$\mathrm{Cu}$ & 0,06 & 0,03 \\
$\mathrm{Zn}$ & 0,13 & 0,04 \\
$\mathrm{Se}$ & 0,01 & 0,00 \\
$\mathrm{Br}$ & 0,01 & 0,11 \\
$\mathrm{Rb}$ & 0,01 & 0,03 \\
$\mathrm{Sr}$ & 0,01 & 0,01 \\
$\mathrm{~Pb}$ & 0,04 & 0,04 \\
& &
\end{tabular}

Figura 5. Média da concentração elementar em $(\mathrm{g} / \mathrm{m} 3)$ durante todo o período de amostragem. 


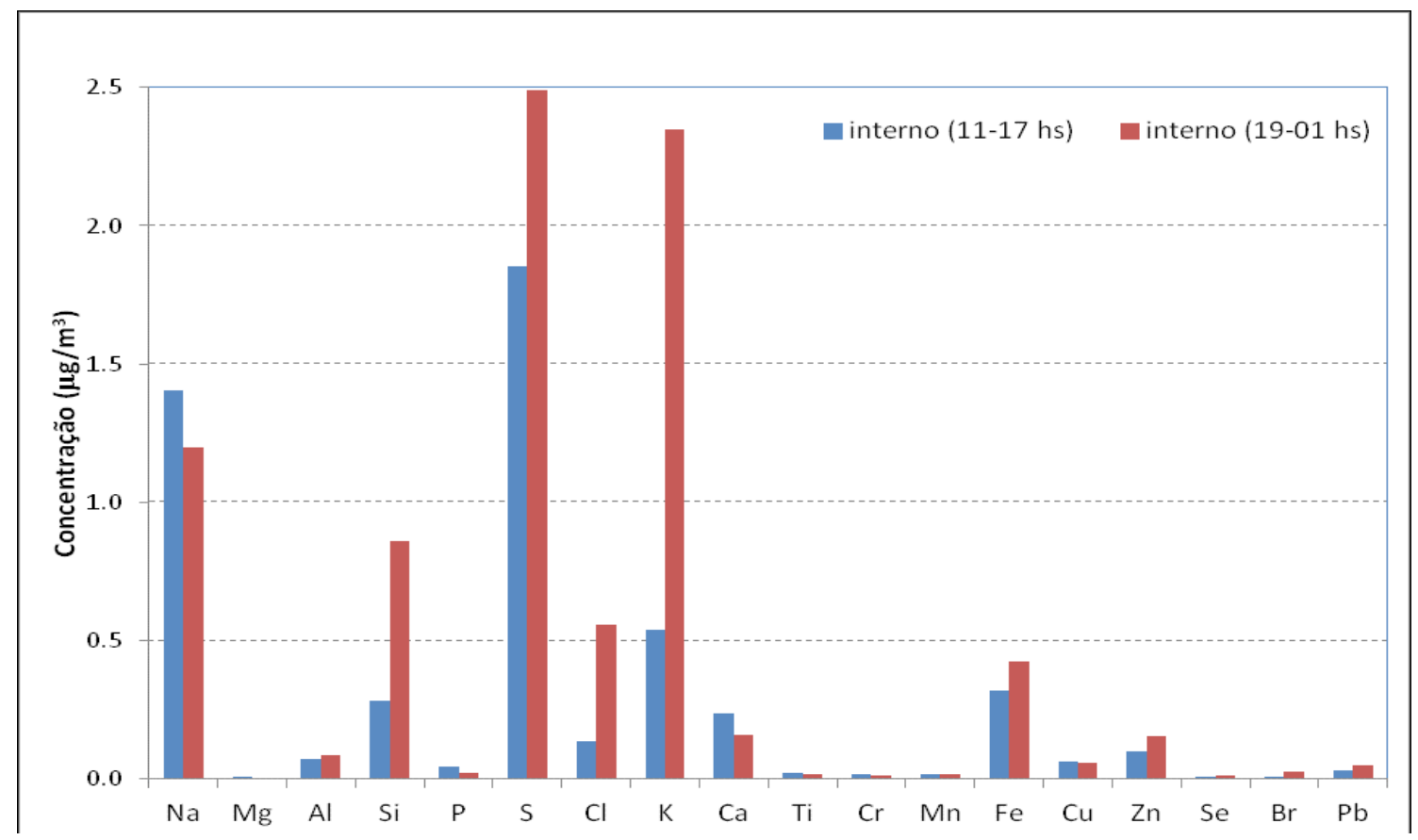

Figura 6. Concentração elementar dentro da pizzaria

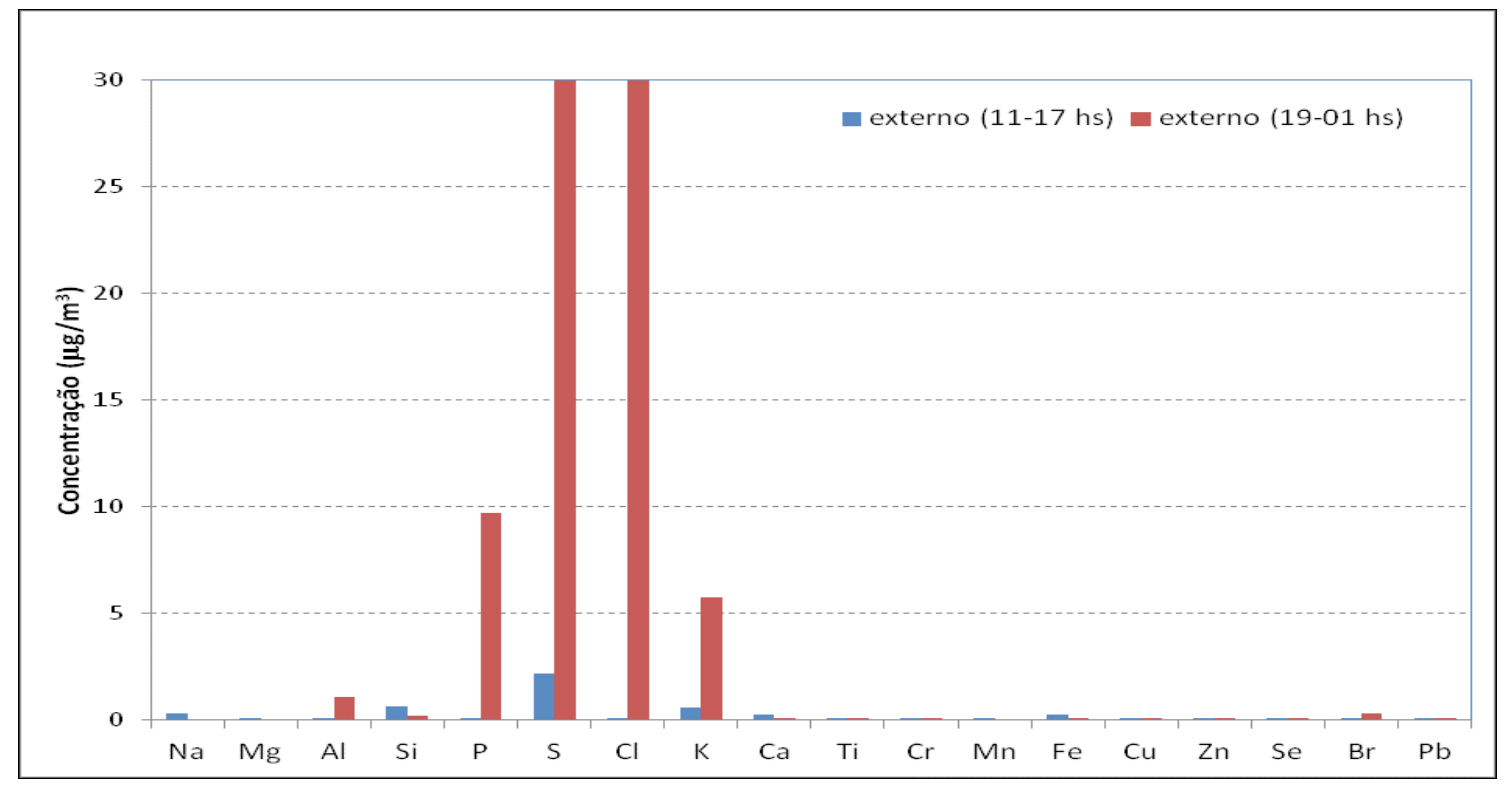

Figura 7. Concentração elementar fora da pizzaria

\section{Conclusão}

Com base nas informações encontradas, são poucos os estudos referentes à temática tratada (no Brasil não existem estudos). Já a questão de poluição de ambientes interiores embora seja relativamente recente, e já exista no Brasil, ainda não possui estudos acerca do ar em pizzarias.

As pizzarias possuem o potencial risco de emitirem para a atmosfera material particulado, monóxido de carbono, dióxido de carbono, compostos orgânicos voláteis e os óxidos de enxofre e nitrogênio, podendo agravar problemas ambientais como efeito estufa e chuva ácida.

Portanto, sendo a prática de cocção de pizza uma atividade de potencial risco poluidor para a atmosfera, e também para quem manuseia e está exposto ao ambiente interno de pizzarias. A exposição ao material particulado tem o poder de causar de um simples desconforto ao aparecimento de doenças que por vez, em casos mais extremos podem levar a morte.

No entanto, uma maior eficiência do exaustor diminui o risco, e que exaustores mais largos, possibilita maior ascensão do material particulado, acarretando 
uma maior dispersão dos poluentes através da chaminé. Outro parâmetro importante diz respeito ao tipo de material que está no forno a ser cozido, influenciando no tipo e quantidade do material particulado a ser emitido, por exemplo, altas concentrações de sódio e potássio presente em queijos.

Os resultados das amostras revelaram altas concentrações de MP2,5, sendo estas mais acentuadas para o ambiente externo, isso devido ao duto acoplado a chaminé, (que diferente do ambiente interno onde ocorreu a dispersão pelo ambiente e trocas gasosas com o ambiente externo através da porta) a fumaça foi canalizada em uma única direção, aumentando a concentração e por consequência o entupimento dos filtros.

\subsection{Sugestões para trabalhos futuros}

Tendo em vista o pioneirismo do estudo em pizzarias, a metodologia desenvolvida necessita de melhor adequação para posteriores estudos. Este trabalho possibilitará o desenvolvimento de futuras amostragens, com equipamentos e materiais que permitam chegar a conclusões mais definitivas.

O MiniVol portable, parece não ser o aparelho mais adequado para a amostragem, talvez outro equipamento e com medida também para MP10, assim como a necessidade de filtros de outro material que não seja de policarbonato. O intervalo entre a troca de filtros não foi suficiente, sugerindo que menores intervalos de tempo possam vir a garantir resultados mais representativos, assim como um maior tempo de amostra, não apenas 4 dias.

Além da questão metodológica, o assunto em questão pode ser complementado por estudos que explorem melhor o tema, por exemplo, uma análise apenas da combustão da lenha (sem pizza no forno), uma vez que, conforme o estudo bibliográfico mostrou, o tipo de material que vai para o forno interfere no tipo e quantidade de material particulado emitido, conseguindo assim uma análise apenas da biomassa queimada.

Muitas doenças, principalmente as pulmonares, estão relacionadas à qualidade do ar. Ora, em que medida as emissões por forno de pizzaria contribuem para esse número?

Por fim, devido ao grande número de churrascarias e padarias na cidade que também fazem uso da lenha e carvão, e após o levantamento do número de estabelecimentos, um estudo comparativo entre pizzarias, churrascarias e padarias estimando o quanto cada um contribui (Fator de Emissão) para a poluição do ar.

Conclui-se que, apesar de alguns problemas técnicos e metodológicos, o trabalho foi de grande importância devido ao pioneirismo do estudo no Brasil e poderá "abrir portas" para estudos avançados.

\section{Agradecimentos}

Ao Instituto de Astronomia, Geofísica e Ciências Atmosféricas da USP (IAG) e ao Laboratório de Análises dos processos Atmosféricos LAPAt/IAG pelo uso dos equipamentos de coleta e análise, o meu muito obrigado.

\section{Referências}

ASHRAE, 2007. Heating, Ventilating, and AirConditioning Applications.

BRITO, J.O. O uso energético da madeira. Estudos Avançados. São Paulo, vol.21, n. 59, 2007.

BIRD, Colin. Química Ambiental. 2. ed. Porto Alegre: Bookman, 2002.

BRAUER, M., HIRTLE, R., LANG, B., OTT, W., 2000. Assessment of indoor fine aerosol contributions from environmental tobacco smoke and cooking with a portable nephelometer. Journal of Exposure Analysis \& Environmental Epidemiology 10, $136 \mathrm{e} 144$

BUONANNO, G., MORAWSKA, L., STABILE, L., 2009a. Particle emission factors during cooking activities. Atmospheric Environment 43, 3235 e 3242.

CONAMA- Conselho Nacional do Meio Ambiente:Brasil.Resolução $\mathrm{N}^{\circ} .003$ de Julho de 1990.4. th ed, Brasília.

\section{CONGRONG HE, LIDIA MORAWSKA, JANE} HITCHINS, DALE GILBERT, 2004. Contribution from indoor sources to particle number and mass concentrations in residential houses. Atmospheric Environment 38 (2004) 3405-3415.

FORSARI FILHO, N. et al. Alterações do meio físico decorrentes de obras de engenharia. São Paulo: Instituto de Pesquisas Tecnológicas, 1992.

FRANCO, N.J.N.; Aplicação de um modelo de trajetórias na simulação de transportes de radionuclídeos na atmosfera. Tese de Doutorado. Universidade Federal do Rio de Janeiro, 2005.

GIODA e AQUINO NETO. Poluição química relacionada ao ar de interiores no Brasil. Quim. Nova, Vol. 26, No. 3, p. 359-365, 2003.

HEINTZENBERG, J. 1982. Size segregated measurements of particulate elemental carbon and aerosol light-absorption at remote artic locations. 
Atmoshperic Environment 16(10): 2461-2469.

HUSSEIN, T., GLYTOS, T., ONDRACEK, J., DOHANYOSOVA, P., ZDIMAL, V., HAMERIO, K.,LAZARIDIS, M., SMOLIK, J., KULMALA, M., 2006. Particle size characterization and emission rates during indoor activities in a house. Atmospheric Environment 40, 4285 e 4307.

KEMP, D.D. 1994. Global Environmental Issues, A climatological approach. Routledge, $224 \mathrm{p}$.

MELLO, H.L.; Controle da poluição atmosférica, Universidade Federal de educação e tecnologia de Santa Catarina, 2005.

Ministério da Saúde, Portaria 3523 de 28 de agosto de 1998.

REZENDE, G. C.; FONSECA, E. P. Implantação da cultura do eucalipto. In: Informe agropecuário, v.12, n.141, p.2024, 2004.

SALDIVA, P. Air pollution and our lung disease patients. J Bras Pneumol., 34(1):1, 2008.

SEBRAE. Idéias de Negócios - pizzaria, 2009.

SEINFELD, J. H. e PANDIS S. N. 1998. Atmospheric chemistry and physics: from air pollution to climate change. John Wiley \& Sons, NY, 1326 pp.

UFMG, Universidade Federal de Minas Gerais. A química da Madeira, 2003. 